Atmos. Chem. Phys. Discuss., doi:10.5194/acp-2015-995, 2016

Manuscript under review for journal Atmos. Chem. Phys.

\title{
The impact of the diurnal cycle of the atmospheric boundary layer on physical variables relevant for wind energy applications
}

\author{
Antonia Englberger ${ }^{1}$ and Andreas Dörnbrack ${ }^{1}$ \\ ${ }^{1}$ Institut für Physik der Atmosphäre, DLR Oberpfaffenhofen \\ Correspondence to: Antonia Englberger (Antonia.Englberger@dlr.de)
}

\begin{abstract}
This paper provides a quantification of the temporal evolution of physical variables in the atmospheric boundary layer (ABL) relevant for wind energy applications. For this purpose, we use the unique dataset gathered during the BLLAST (Boundary Layer Late Afternoon and Sunset Turbulence) field experiment to validate a large-eddy simulation (LES) model by simulating the complete diurnal cycle of the ABL. In this way, this contribution to the special issue of ACP 'The Boundary-Layer Late Afternoon and Sunset Turbulence project' satisfies the purpose of the BLLAST experiment: to provide a dataset for the validation of numerical simulations aiming to study transient BL processes. For wind energy applications, we are investigating the behaviour of different physical parameters which are relevant in the height region where a wind turbine operates. This results in a quantification of the diurnal cycle influence on the vertical wind shear, the stratification and the turbulence intensity in the atmosphere. Further, the impact of different heterogeneous surface conditions on shear near the surface layer of the ABL is investigated.
\end{abstract}

\section{Introduction}

The ABL is characterised by a diurnal cycle, which is forced by the solar irradiation, heating the

Earth's surface during daytime and the infrared radiation to space, cooling the Earth's surface during night. It is additionally influenced by mesoscale and synoptic scale external forcings. The diurnal cycle (Stull (1988), p 11, Fig. 1.7) is composed of the stable boundary layer (SBL) at night and the convective boundary layer (CBL) or neutral boundary layer (NBL) during daytime. In between the night and day regimes different transient periods exists which are named morning (MT), afternoon (AT) and evening transition (ET), respectively.

The diurnal cycle is influenced in detail by the following physical processes (Stull (1988)): During the night, when the surface fluxes are rather low, the BL consists of an SBL capped by a neutrally stratified layer, the residual layer (RL). The RL results from the decay of turbulence of the CBL of the previous day. The SBL is characterised by a small turbulence intensity, because the eddies 
Atmos. Chem. Phys. Discuss., doi:10.5194/acp-2015-995, 2016 fluxes from its minimum level initiate the onset of the MT. The heating of the surface generates thermals which erode the stable layer from below. During the MT, the turbulent eddies increase in size and strength and start to form a fully convective layer, which continues to grow throughout the morning. During this transition period, the mixed layer incorporates the RL from the previous night. After this process called free encroachment (Sorbjan (2004)) has happened, a fully developed CBL evolves from the MT and is present during daytime. In contrast to the SBL, the CBL is characterised by a larger amount of turbulence, which is generated by the domination of buoyancy over shear. The buoyancy results from upward motion of air in thermal plumes initiated by a positive heat flux from the surface. The CBL is not only influenced from below, entrainment processes incorporate non-turbulent air from the free atmosphere above. These processeses involve fluxes of heat, mass, momentum and moisture across the BL top. The updraughts and downdraughts lead to convective motions in the CBL, which are suppressed by the stratification of the atmosphere in the SBL. When the forcing at the surface declines due to decreasing heat fluxes, the afternoon transition sets in.

Different definitions of the onset of the AT exist (e.g. Nadeau et al. (2011), Grimsdell and Angevine (2002)). We consider as AT the time from the decrease of the surface sensible heat flux up to the time the ET sets in. The onset of the ET is initiated as the time approaching zero sensible heat flux at the surface (e.g. Grimsdell and Angevine (2002)). During the ET, the decaying CBL merges into the SBL and a RL above the SBL, closing the diurnal cycle.

45

The behaviour of this diurnal cycle of the ABL has been studied since the 1970s. There are many studies (observational and numerical) regarding the SBL (e.g. Nieuwstadt (1984), Carlson and Stull (1986), Mahrt (1998)) or especially the RL (e.g. Balsley et al. (2008), Wehner et al. (2010)). Also the CBL has been investigated intensively over the last decades with different focuses, e.g. on entrainment (e.g. Sorbjan (1996), Sullivan et al. (1998) and Conzemius and Fedorovich (2007)) and on shear (e.g. Moeng and Sullivan (1994), Fedorovich et al. (2001), Pino et al. (2003) and Pino et al. (2003)). Deardorff (1974a) and Deardorff (1974b) performed the first LES of a transition process in the ABL. Since then, many LES of the transitional phases have been performed on the MT (e.g. Sorbjan (2007) and Beare (2008)) as well as the AT (e.g. Sorbjan (1997), Sorbjan (1996), Beare et al. (2006) and Pino et al. (2006)).

Regarding the different performed studies, we address as first research question:

(i) Is it possible to validate the complete diurnal cycle of the ABL for the BLLAST dataset with our LES model EULAG?

The reason to ask this question is the known strong influence of the diurnal cycle on the physical quantities in the lowest $200 \mathrm{~m}$ of the ABL (Emanuel et al. (2015)). Therefore, a validated numerical method is required to provide reliable profiles during the whole day, especially in the transition 
Atmos. Chem. Phys. Discuss., doi:10.5194/acp-2015-995, 2016

Manuscript under review for journal Atmos. Chem. Phys.

phases. The interaction of the ABL turbulence with wind turbine wakes is only poorly understood due to the complexity of the ABL (Naughton et al. (2011), Emeis (2013), Emeis (2014)). This paper can be considered as an investigation to prepare LESs of wind turbine wakes subject towards realistic ABL regimes. Therefore, the BLLAST dataset is used to validate our results and to compare them with the accompanying numerical simulations published in ACP (e.g. Blay-Carreras et al. (2014), Nilsson et al. (2015)).

According to both, experimental studies (e.g. Medici and Alfredsson (2006), Chamorro and PortéAgel (2009), Zhang et al. (2012)) and numerical simulations (e.g. Troldborg et al. (2007), Wu and Porté-Agel (2012)) of wind turbines, the inflow wind field a wind turbine is exposed to strongly influences the wake structure and the turbine loading, both affecting the power production of a wind turbine. Therefore, the wake structure strongly depends at least on the following three physical parameters: the vertical wind shear, the stratification of the atmosphere and the amount of turbulence in the atmosphere. These parameters, however, strongly vary in the different phases of the diurnal cycle (Stull (1988)). There are experimental studies considering different atmospheric stratifications (NBL, SBL, CBL) (e.g. Medici and Alfredsson (2006), Chamorro and Porté-Agel (2010), Zhang et al. (2012), Tian et al. (2013), Zhang et al. (2013)). In most of the numerical simulations of an individual wind turbine, however, an NBL is assumed (e.g. Wu and Porté-Agel (2011), Porté-Agel et al. (Chapel Hill, 2010), Naughton et al. (2011), Englberger and Dörnbrack (2015)). There are approaches considering the SBL (Aitken et al. (2014)) or the CBL (Mirocha et al. (2014)) in a one-way nested Weather Research and Forecasting (WRF)-LES simulation. Some recent LES studies start to investigate the impact of an SBL on the wake (Bhaganagar and Debnath (2014) and Bhaganagar and Debnath (2015)). However, to our knowledge, no study has been performed so far investigating the influence of all the phases of the diurnal cycle, including the CBL and the transitions. Therefore, the second research question is:

(ii) Which impact have the individual phases of the diurnal cycle on the physical variables relevant for wind energy applications?

This study is performed as an intermediate step towards an investigation placing an emphasis on the interaction of the different atmospheric stratifications with the flow field behind a wind turbine. Such a study is necessary, as the effect of different atmospheric conditions on the wake is varying over the course of the diurnal cycle and the propagation and dissipation of the wake is not well understood up to now (Emanuel et al. (2015)).

Most of the performed LES simulations on the characteristics of the BL, mentioned above, prescribe homogeneous surface conditions. However, the Earth's surface is not homogeneous. It is strongly affected by different land use, buildings, and so on. Therefore, considering heterogeneous surface conditions will especially improve the turbulence structure close to the ground. According to e.g. 
Atmos. Chem. Phys. Discuss., doi:10.5194/acp-2015-995, 2016

Manuscript under review for journal Atmos. Chem. Phys.

Published: 26 January 2016

(c) Author(s) 2016. CC-BY 3.0 License.

Stull (1988), Moeng and Sullivan (1994) or Beare (2008), the diurnal cycle is affected by different stratifications of the atmosphere which have a large impact on the amount of turbulent kinetic energy (TKE) in the BL. At daytime, the TKE budget is dominated by a buoyancy driven structure, whereas at night shear dominates. The buoyancy results from the applied surface fluxes. The shear is influenced by the surface heterogeneity. For example, according to Dörnbrack and Schumann (1993), for ratios of the friction velocity $u_{*}$ to the convective velocity scale $w_{*}$ larger than 0.35 shear becomes important over heterogeneous surfaces. The main effect of a heterogeneous surface on shear arises close to the ground, in the area relevant for wind energy applications. This results in our third research question:

(iii) Which impact has the heterogeneity of the surface on shear, contributing to the TKE budget, in a region relevant for wind energy applications?

The results of this study pave the groundwork for future work in analysing the interaction of a wind turbine in a turbulent boundary layer under different atmospheric stratifications and a realistic heterogeneous surface.

The outline of the paper is as follows. The numerical model, the diurnal cycle representation, the applied external forcings and the heterogeneous surface method are described in chapter 2 . The observations, the numerical experiment and the validation of the complete diurnal cycle for the BLLAST dataset with our LES model EULAG are presented in chapter 3. Chapter 4 investigates the impact of the individual phases of the diurnal cycle on different physical variables relevant for wind energy applications. Chapter 5 explores the impact the surface heterogeneity on shear. The discussion of the paper is presented in chapter 6 and a summary is given in chapter 7 .

\section{Framework}

\subsection{Numerical model}

The ABL is simulated with our numerical model EULAG, which is at least of second order accuracy

in time and space and well suited for massively-parallel computations (Prusa et al. (2008)). It can be run parallel up to a domain decomposition in three dimensions. The name EULAG refers to the ability of solving the equations of motions either in an EUlerian (flux form) (Smolarkiewicz and Margolin (1993)) or in a semi-LAGrangian (advective form) (Smolarkiewicz and Pudykiewicz (1992)) mode. A comprehensive description and discussion of EULAG can be found in Smolarkiewicz and Margolin (1998) and Prusa et al. (2008).

For the following simulations, the Boussinesq equations for a flow with constant density $\rho_{0}=$ $1.1225 \mathrm{~kg} \mathrm{~m}^{-3}$ are used and the environmental state $\left(\Theta_{0}\right)$ is described by an isotherm with $\Theta_{0}=$ 
Atmos. Chem. Phys. Discuss., doi:10.5194/acp-2015-995, 2016

$301 \mathrm{~K}$. The governing equations are written for velocity components in Cartesian coordinates in

$$
\begin{aligned}
\frac{d \mathbf{v}}{d t} & =-G \boldsymbol{\nabla}\left(\frac{p^{\prime}}{\rho_{0}}\right)+\mathbf{g} \frac{\Theta^{\prime}}{\Theta_{0}}+\mathcal{V}+\mathbf{M}+\mathbf{F}_{v}-\alpha_{m} \mathbf{v} \\
\frac{d \Theta^{\prime}}{d t} & =\mathcal{H}+F_{\Theta}-\alpha_{h} \Theta^{\prime} \\
\nabla \cdot\left(\rho_{0} \mathbf{v}\right) & =0
\end{aligned}
$$

Here, $\frac{d}{d t}, \nabla$ and $\nabla \cdot$ represent the total derivative, the gradient and the divergence. $\mathbf{v}$ denotes the physical velocity vector, $p^{\prime}$ the pressure perturbation with respect to the environmental state, $\mathbf{g}$ the gravitational acceleration and $\rho_{0}$ the density of the fluid. $\Theta^{\prime}$ is the deviation of the potential temperature $\Theta$ from the environmental state of the atmosphere $\Theta_{0}$. $G$ represents the Jacobian of the transformation which result from the general, time-dependent coordinate transformation (Smolarkiewicz and Prusa (2005), Prusa et al. (2008)). The subgrid scale terms $\mathcal{V}$ and $\mathcal{H}$ symbolise viscous dissipation of momentum and diffusion of heat. $\mathbf{M}$ denotes the inertial forces of coordinate-dependent metric accelerations. $\mathbf{F}_{v}$ and $\mathrm{F}_{\Theta}$ are the additional forcing applied on the wind and the potential temperature perturbation. The relaxation terms $\alpha_{m}$ and $\alpha_{h}$ are used to represent a heterogeneous surface. The surface obstacle elements are included via the immersed boundary method (Smolarkiewicz et al. (2007)). This method mimics the presence of solid structures and internal boundaries by applying the fictitious body forces $-\alpha_{m} \mathbf{v}$ in Equation (1) and $-\alpha_{h} \Theta^{\prime}$ in Equation (2). In the fluid away from the solid boundaries $\alpha_{m}$ and $\alpha_{h}$ are both zero, whereas they are approaching $\frac{1}{2} \Delta t$ within the solid assuring the velocity to approach zero. $\Delta t$ represents the time step.

In general, EULAG owes its versatility to a unique design that combines a rigorous theoretical formulation in generalized curvilinear coordinates (Smolarkiewicz and Prusa (2005)) with nonoscillatory forward-in-time (NFT) differencing for fluids built on the multidimensional positive definite advection transport algorithm (MPDATA), which is based on the convexity of upwind advection (Smolarkiewicz and Margolin (1998); Prusa et al. (2008)) and a robust, exact-projection type, elliptic Krylov solver (Prusa et al. (2008)). The flow solver has been applied to a wider range of scales simulating various problems like turbulence (e.g. Smolarkiewicz and Prusa), flow past complex or moving boundaries (e.g. Kühnlein et al. (2012)), gravity waves (e.g. Doyle et al. (2011)) or even solar convection (e.g. Smolarkiewicz and Charbonneau (2013)).

\subsection{Diurnal cycle representation}

The simulations of an SBL and a CBL have to meet different requirements. For the simulation of an SBL, a fine spatial resolution is needed to represent the small size eddies and a small domain is sufficient. A CBL simulation, however, requires a large enough domain to capture the convective 

combining these results in a large domain with a rather fine resolution. However, this is a computationally very expensive approach. Therefore, for the transition from an SBL towards a CBL, the domain expansion method from Beare (2008) is applied. For the transition back from the coarse to the fine resolution the domain size cannot simply be decreased again, as the same physical situation should be represented until the end of the simulation. Therefore, the domain size is kept constant and the resolution is decreased by performing an interpolation procedure. Both transition methods are conducted in two steps separated by one hour of physical time to limit numerical instabilities. We, hereafter, refer to them as MT method and ET method. In Table 1 the spatial horizontal resolutions and domain sizes for the corresponding atmospheric regimes are listed.

\subsection{External forcings}

The diurnal cycle is controlled by the heating or cooling of the Earth's surface, described by surface fluxes. To simulate the diurnal cycle realistically, additional external forcings as mesoscale and synoptic scale processes have to be modelled and integrated into the LES, which is a computationally expensive process. The alternative we choose for this paper is to incorporate external forcings via physical parameterisations in the LES. In this investigation we include subsidence (S) and radiative cooling as large-scale processes.

The surface fluxes prescribe the diurnal heating cycle, with a cooling at night and a warming during daytime. In general, a sinusoidal like function is assumed with the maximum value occurring at the time around noon corresponding to the maximum in solar irradiation (e.g. Sorbjan (2007), Beare (2008)). The solar or infrared irradiation value divided by $\rho_{0}$ and the specific heat capacity at constant pressure corresponds to the surface fluxes, which are contributing to Equation (2). The surface fluxes in the lowest level are controlled by the subgrid-scale model. In all other levels we vertically distribute the surface fluxes with height with an e-folding scale of $300 \mathrm{~m}$ via $S F \cdot \exp \left(-\frac{z}{300 \mathrm{~m}}\right)$.

The subsidence process is a large-scale process, representing the main physical mechanism responsible for the decent of the CBL height. According to Mazzitelli et al. (2014), subsidence does not only affects the height of the CBL it also influences the turbulent fluctuations within the CBL. The subsidence process is important in simulations aiming at a realistic simulation of the ABL to match actual measurements of temperature and turbulence in the atmosphere. In general, subsidence acts on the zonal and meridional wind components $u$ and $v$, as well as on the potential temperature $\Theta$. It can be modelled by the product of a subsidence velocity $w_{s u b}$ and the vertical derivative of the wind components or temperature, according to Equation (4). Here, $\xi$ equals $u$ and $v$ in Equation (1) and 
$\Theta^{\prime}$ in Equation (2).

$S_{i, j, k}^{\xi}=w_{s u b} \frac{d \xi}{d z}=w_{s u b} \frac{\xi_{i, j, k+1}-\xi_{i, j, k}}{z_{i, j, k+1}-z_{i, j, k}}$

The indices of the grid points are denoted by $i=1 \ldots n, j=1 \ldots m$, and $k=1 \ldots l$ in the $x, y$ and $z$ directions, respectively. The velocity $w_{s u b}$ determines the strength of subsidence, with a larger subsidence velocity resulting in a lower CBL height. In the following simulations, the subsidence velocity is constant with height with $\mathrm{S}_{i, j, k}$ acting in all levels and grid points besides at the ground and the top. The parameterisation acts as $S^{u}=F_{u}$ and $S^{v}=F_{v}$ in Equation (1), whereas $S^{\Theta}$ is another contribution of $F_{\Theta}$ in Equation (2).

There are different parameterisations of the subsidence process. An increase of $w_{\text {sub }}$ from zero at the ground up to a maximum value of the order of $\mathcal{O}\left(10 \mathrm{~mm} \mathrm{~s}^{-1}\right)$ at the top of the BL and a constant value of this maximum in the free atmosphere is typically used in the literature (e.g. Blay-Carreras et al. (2014)). We use a constant subsidence velocity to result in a larger effect of subsidence in the lower levels. This is motivated as we have no knowledge about individual processes resulting in a height dependent subsidence velocity. A parameterisation is considered to be reasonable if it reaches the maximum of subsidence at the top of the boundary layer in order to control the height of the BL top. Equation (4) verifies this requirement because the vertical gradient $\frac{d \xi}{d z}$ maximises at the transition from the BL to the inversion layer. This dependence controls the height of the BL, whereas the magnitude of the subsidence velocity influences the strength of this change.

The applied subsidence on the potential temperature in Equation (2) does not only result in a decrease of the boundary layer height, it also warms the boundary layer air. Therefore, radiative cooling has to be considered as another large-scale process in order to compensate the additional warming making the simulations conform with the measurements. In our simulations radiative cooling is constant with height and acts in all levels and grid points besides at the ground and the top. It is also applied on $\mathrm{F}_{\Theta}$ in Equation (2), resulting in $F_{\Theta}=S F \cdot \exp \left(-\frac{z}{300 m}\right)+S^{\Theta}+\left.\frac{\partial \Theta}{\partial t}\right|_{\text {rad }}$ for $z>0$.

\subsection{Surface heterogeneity}

The main simulation is performed with a homogeneous surface, a drag coefficient of 0.1 and a horizontally homogeneous momentum flux prescribed over the complete domain. In three additional simulations, a heterogeneous surface is applied to analyse the impact of the surface heterogeneity on the ABL. The main surface characteristics are listed in Table 2. In simulation B, cubic obstacles with a size of $100 \mathrm{~m} \times 100 \mathrm{~m} \times 5 \mathrm{~m}$, separated by $100 \mathrm{~m}$ from each other in zonal and meridional direction, are implemented via the immersed boundary method in Equations (1) and (2). These obstacles are acting for example as individual patches of different land use or buildings. To test the sensitivity of the obstacles, simulation B is repeated with two times the height of the obstacles in simulation C 
Atmos. Chem. Phys. Discuss., doi:10.5194/acp-2015-995, 2016

Manuscript under review for journal Atmos. Chem. Phys.

$(100 \mathrm{~m} \times 100 \mathrm{~m} \times 10 \mathrm{~m})$. In simulation $\mathrm{D}$, the area covered by the obstacles is modified, whereas the size of the obstacles stays the same as in simulation B. Here, the obstacles are separated by $200 \mathrm{~m}$ from each other, leading to one fourth of the area covered by cubes in comparison to simulation $\mathrm{B}$. In all modified simulations (B to D), local variations regarding the momentum flux are prevalent.

\section{Diurnal cycle validation}

\subsection{Observations}

The BLLAST field campaign took place from 14 June to 8 July 2011 in southern France at Lannemezan, an area of complex terrain a few kilometre from the Pyrenean foothills. The heterogeneous surface in the plateau is covered by grass, meadows, crops and forest. Measurements from towers, radiosondes, airplanes and ground-based remote sensing are recorded during the whole campaign, with twelve intensive observing periods (IOPs), characterised by various meteorological conditions. A detailed description can be found in Lothon et al. (2014).

We use the IOP of the BLLAST campaign from the 1st of July 2011 (Lothon et al. (2014)) for the validation of our method of the simulation of a diurnal cycle with the LES model EULAG. We chose the 1st of July because it is characterised by anticyclonic conditions minimising large-scale forcings except subsidence and radiative cooling. The lower troposphere is governed by a mountain-plain circulation along the valley with almost no clouds prevalent. The data of four radiosonde launches at 0000 UTC, 1100 UTC, 1658 UTC and 2254 UTC are available for the 1st of July 2011.

\subsection{Numerical experiment}

Our diurnal cycle simulation is initialised with the potential temperature data from the 0000 UTC radiosonde launching. The development of the meteorological fields with time are compared to and validated against the other three measurements. Our numerical simulation runs for $23 \mathrm{~h}$, starting with the SBL, including the MT, the CBL phase, the AT, the ET and finishing with the SBL, modelling a complete diurnal cycle of the ABL.

By performing the diurnal cycle method for a simulation of the complete day, we start the SBL simulation with a domain size of $793.75 \mathrm{~m} \times 793.75 \mathrm{~m} \mathrm{x} 3 \mathrm{~km}$, resulting in a domain size of $3.175 \mathrm{~km}$ $x 3.175 \mathrm{~km} \times 3 \mathrm{~km}$ after the MT up to the end of the simulation, following Table 1 . The vertical resolution is set to $5 \mathrm{~m}$ in the first $200 \mathrm{~m}$, increased to $10 \mathrm{~m}$ up to $800 \mathrm{~m}$ and $20 \mathrm{~m}$ to the domain top at $3 \mathrm{~km}$.

The flux measurements are taken from a $60 \mathrm{~m}$ tower with values at $30 \mathrm{~m}, 45 \mathrm{~m}$ and $60 \mathrm{~m}$ altitude. The sensible heat flux at the surface is calculated via an e-folding scale of $300 \mathrm{~m}$ and the measure- 
Atmos. Chem. Phys. Discuss., doi:10.5194/acp-2015-995, 2016

Manuscript under review for journal Atmos. Chem. Phys.

Published: 26 January 2016

(c) Author(s) 2016. CC-BY 3.0 License.
Atmospheric

Chemistry

and Physics

Discussions

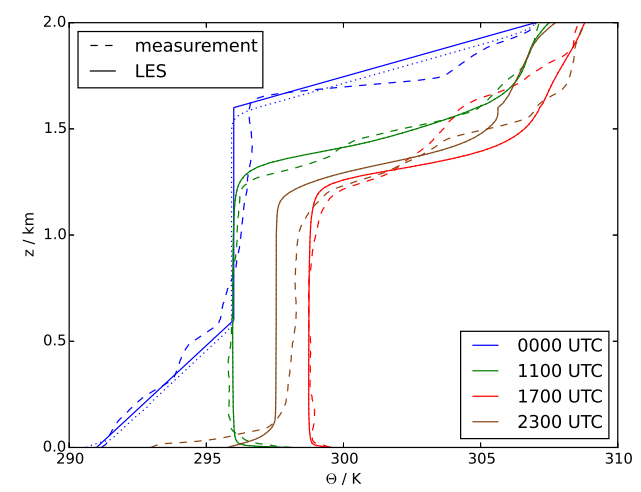

Figure 1. The evolution of the area-averaged $\Theta(z)$ is plotted with the corresponding radiosonde measurements at 0000 UTC, 1100 UTC, 1700 UTC and 2300 UTC for the lowest $2 \mathrm{~km}$. The initial starting profile is also plotted for 0000 UTC.

ments at these heights. The temporal evolution of the measurements is set symmetric around 1200 UTC with a maximum of roughly $140 \mathrm{~W} \mathrm{~m}^{2}$ at noon.

The height of the boundary layer is controlled by the application of the requested amount of subsidence. The amount of subsidence is calculated from the BL height derived from the potential temperature profiles from the four radiosonde ascents (Fig. 1). Up to the ET sets in, $w_{\text {sub }}=-10 \mathrm{~mm} \mathrm{~s}^{-1}$. In the following SBL phase, $w_{\text {sub }}$ approaches zero as the height of the BL stays at the same height. Due to the effect of subsidence on temperature, we applied radiative cooling of the atmosphere. The prescribed amount of radiative cooling arises from the difference of the simulated potential temperature profile of a precursor simulation without radiative cooling from the corresponding measured profile in Fig. 1. The radiative cooling $\left.\frac{\partial \Theta}{\partial t}\right|_{\text {rad }}$ corresponds to roughly $-2 \mathrm{~K} \mathrm{~d}^{-1}$. According to the BLLAST dataset, the maximum of the wind in $100 \mathrm{~m}$ is roughly $3 \mathrm{~m} \mathrm{~s}^{-1}$ at the 1 st of July 2011 . This is a rather low wind at hub height of a wind turbine. Therefore, we set the zonal wind to a constant geostrophic wind of $10 \mathrm{~m} \mathrm{~s}^{-1}$ and the meridional wind to zero at 0000 UTC. This allows an investigation of the atmospheric conditions under appropriate requirements for wind energy. Further, the simulations are dry and do not consider any moisture effects or latent heat fluxes.

\subsection{Validation of the complete diurnal cycle}

Here, we focus on the diurnal variation of the boundary layer height which is best represented by the temporal evolution of the inversion height. This altitude is taken as a measure which should be reproduced as precisely as possible for the different stages of the ABL evolution. The surface fluxes, 
Atmos. Chem. Phys. Discuss., doi:10.5194/acp-2015-995, 2016

subsidence and radiative cooling act as tuning parameters to achieve this goal. It must be noted that the values of the chosen tuning parameters are in a realistic range which can be expected from the available BLLAST observations. A comparison of the simulated $\Theta$ profiles with the radiosonde measurements is shown in Fig. 1.

The potential temperature values are calculated as the horizontal average at each model level. The simulation is initialised with the fit of the observed 0000 UTC potential temperature of profile (blue solid line in Fig. 1). During eleven hours of simulation time, the potential temperature structure changes and a CBL forms. The warming in the lowest $500 \mathrm{~m}$ results from the applied external forcings. The decrease of the CBL height is induced by the subsidence process. The simulated vertical potential temperature profile shows a good agreement with the measurement after eleven hours (green lines in Fig. 1). The transition from a convectively unstable to a well mixed profile occurs a little bit closer to the ground in comparison to the measurement. The amount of subsidence applied is constant with height. Therefore, the structure of the capping inversion shows little differences in the numerical simulations compared to the observed radiosonde profile. After 17 hours, the simulated $\Theta$ profile fits well with the observation for $z<1300 \mathrm{~m}$ (red lines in Fig. 1). Above the inversion, modelled and observed profiles differ. The level of the transition towards a constant potential temperature with height in the 1700 UTC plot is comparable to the 1100 UTC plot. However, in the measurement the height has decreased, leading to a better agreement of the simulation result with the measurement at 1700 UTC. At 2300 UTC, there is a difference prevalent between the measurement and the LES result in the lowest levels. Considering $23 \mathrm{~h}$ of simulation with the restricted ways of prescribed forcings, the deviation is considered to be acceptable (brown lines in Fig. 1). Probably, changing from a constant radiative cooling with height towards less radiative cooling inside the residual layer and a stronger radiative cooling in the SBL could bring the simulated profiles closer to the observed ones. However, the vertical transition from a stably stratified surface layer to a nearly neutrally stratified layer above is well captured by the model.

From this comparison of the individual times of a day with the radiosonde measurements at 1100 UTC, 1700 UTC and 2300 UTC follows a fairly well reproduction of the structure of the potential temperature profiles. This validates our diurnal cycle method, controlled by the three tuning parameters. Our applied method enables to reproduce each diurnal cycle which is affected mainly by these three external forcings by choosing the right values of the tuning parameters.

\section{Impact of the individual phases on physical variables relevant for wind energy}

The individual phases of the diurnal cycle not only have an impact on the potential temperature evolution with time. For wind energy applications, the wind and related to it the prevalent atmospheric 
Atmos. Chem. Phys. Discuss., doi:10.5194/acp-2015-995, 2016

turbulence are the most important atmospheric variables (Naughton et al. (2011), Emeis (2013), Emeis (2014)).

\subsection{Wind and atmospheric turbulence}

The magnitude of the incoming wind and the vertical velocity gradient influence the amount of energy extracted from the flow field by the wind turbine. Atmospheric turbulence influences the rate of entrainment of surrounding air into the wake of a wind turbine. Both, the incoming wind and the atmospheric turbulence have an impact on the structure of the flow field behind the wind turbine and on the forces acting on the blades.

Figures $2 \mathrm{a}, \mathrm{b}$ and $\mathrm{c}$ show the deviation of the zonal wind component $u$ from its mean in a height of $100 \mathrm{~m}$. This is a typical hub height of operating wind turbines. The CBL (1100 UTC as well as 1700 UTC) reveals much stronger fluctuations of the wind around its mean in comparison to the SBL at 2300 UTC. This results in a more turbulent atmosphere during the CBL phase in comparison to the SBL phase. The structure of the CBL as documented in Figs. 2a and b is characterised by lateral elongated convergence lines which propagate with the mean wind through the domain in x-direction. At 1100 UTC several of these lines are distributed nearly randomly over the domain. In contrast, at 1700 UTC one coherent band dominates the flow structure. This structure is induced by the shear close to the surface. The calculation of $\frac{u_{*}}{w_{*}}$, similar to Dörnbrack and Schumann (1993), results in a $50 \%$ larger value of $\frac{u_{*}}{w_{*}}$ at 1700 UTC in comparison to 1100 UTC. In both cases, the value exceeds the threshold of 0.35 , resulting in roll structures (Figs. $2 \mathrm{a}$ and $\mathrm{b}$ ), which are stronger pronounced in Fig. 2b. After levelling down the surface heating, the differences $u-\bar{u}$ decrease and show only little structural organisation in Fig. 2c. The diagonal structure results from the Coriolis effect. It dominates during the SBL phase whereas in the CBL phase the effect of thermals prevails.

The temporal evolution of the resolved TKE for the complete diurnal cycle is presented up to $2 \mathrm{~km}$ in

Fig. 2d. It confirms an increase of the resolved TKE during day. At night and in the free atmosphere the resolved TKE is small all the time. The resolved mean TKE is calculated according to Equation (5) horizontally averaged at each height level after Stull (1988):

$\bar{e}=\frac{1}{2}\left(\overline{u^{\prime 2}}+\overline{v^{\prime 2}}+\overline{w^{\prime 2}}\right)$

The production and reduction of resolved TKE in the transition zones are representing challenging conditions for wind turbine applications.

The rotor of a typical wind turbine has a diameter of roughly $100 \mathrm{~m}$. This results in an operating height of a wind turbine roughly in between $50 \mathrm{~m}$ and $150 \mathrm{~m}$. The amount of the streamwise velocity and the vertical gradient of $u$ between $50 \mathrm{~m}$ and $150 \mathrm{~m}$ are plotted in Fig. 3a as temporal evolution 
Atmos. Chem. Phys. Discuss., doi:10.5194/acp-2015-995, 2016

Manuscript under review for journal Atmos. Chem. Phys.

Published: 26 January 2016

(c) Author(s) 2016. CC-BY 3.0 License.
Atmospheric

Chemistry

and Physics

Discussions
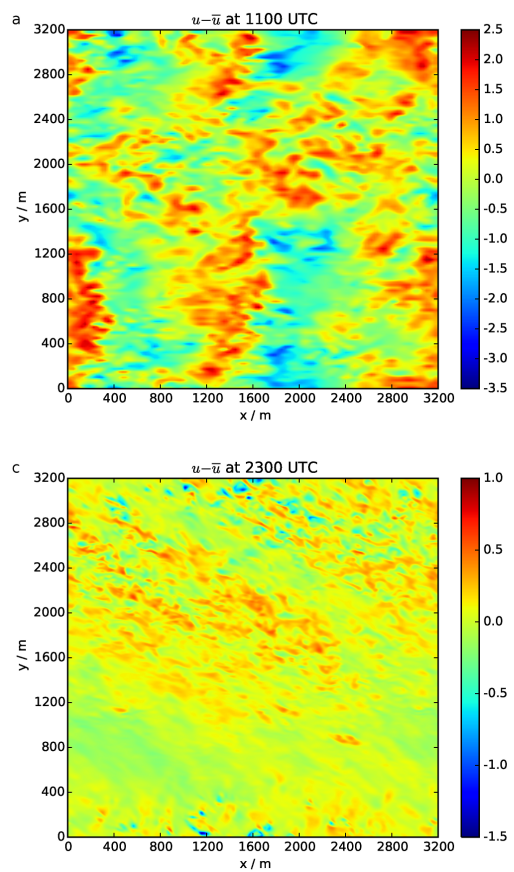
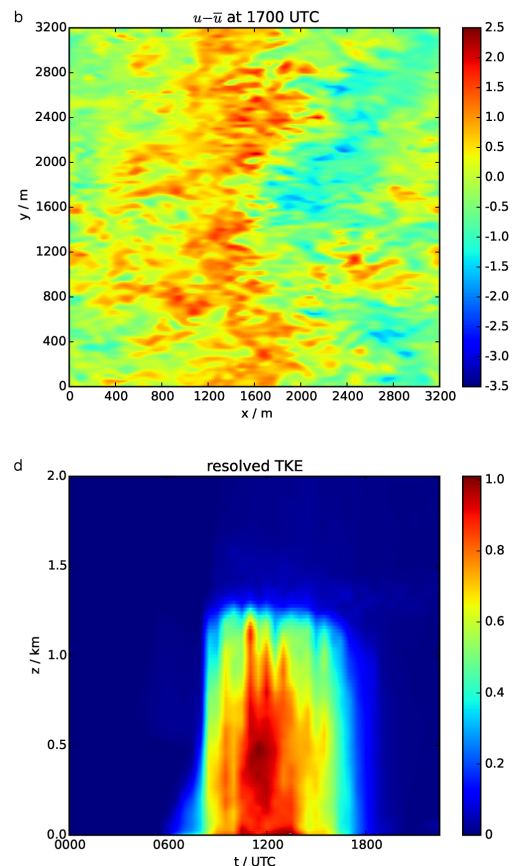

Figure 2. The deviation of the mean zonal velocity in $\mathrm{m} \mathrm{s}^{-1}$ from the instantaneous value at 1100 UTC, 1700 UTC and 2300 UTC in a height of $100 \mathrm{~m}$ in a, b and c. Part $d$ shows the temporal evolution of the resolved TKE up to the top of the inversion layer.

with the mean value, the minimum and the maximum of $u$ within this height range. A striking difference is available between the CBL phase including 1100 UTC and 1700 UTC and the SBL phase including 2300 UTC. The difference in $u$ between the lowest part of the rotor and the highest part is rather small of the order of $\mathcal{O}\left(10^{-2} \mathrm{~m} \mathrm{~s}^{-1}\right)$ in the CBL phase. In the SBL phase, it reaches roughly $\mathcal{O}\left(10^{-1} \mathrm{~m} \mathrm{~s}^{-1}\right)$. The vertical structure of $u$ at 1100 UTC, 1700 UTC and 2300 UTC is shown in Fig. 3b. At 1100 UTC and 1700 UTC the difference is in between $0.1 \mathrm{~m} \mathrm{~s}^{-1}$ and $0.2 \mathrm{~m} \mathrm{~s}^{-1}$, whereas at 2300 UTC the difference is remarkably higher with roughly $1.5 \mathrm{~m} \mathrm{~s}^{-1}$. This difference of one order of magnitude between the day and the night phase is important in wind energy, as the forces acting on the blades depend on the local magnitude of the incoming wind ( $F \approx u^{2}$ (Hansen (2008))). 
Atmos. Chem. Phys. Discuss., doi:10.5194/acp-2015-995, 2016

Manuscript under review for journal Atmos. Chem. Phys.

Published: 26 January 2016

(c) Author(s) 2016. CC-BY 3.0 License.
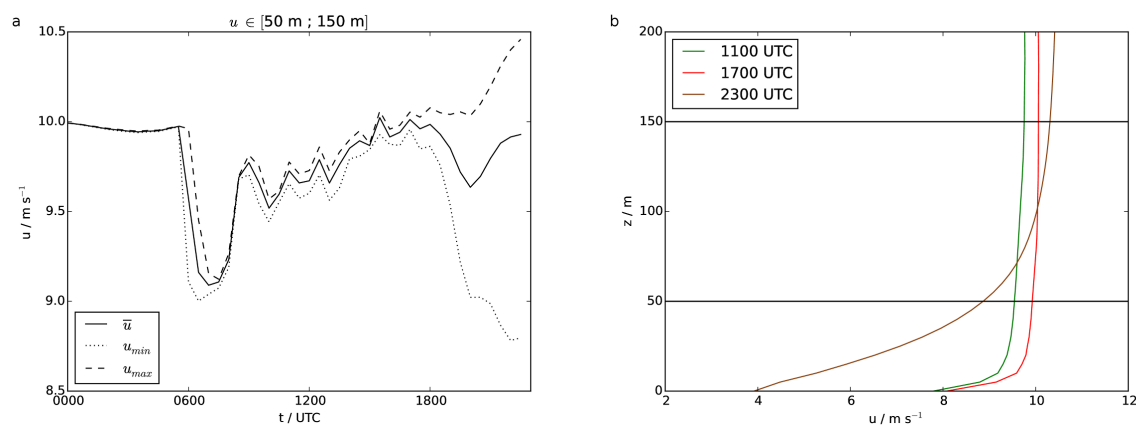

Figure 3. The temporal evolution of the mean value of the zonal wind, as well as its maximum and minimum are shown in a height in between $50 \mathrm{~m}$ and $150 \mathrm{~m}$ in a. In b, the vertical structure of the horizontal averaged zonal wind is plotted for the same height range for 1100 UTC, 1700 UTC and 2300 UTC. The solid lines mark $50 \mathrm{~m}$ and $150 \mathrm{~m}$ in height.
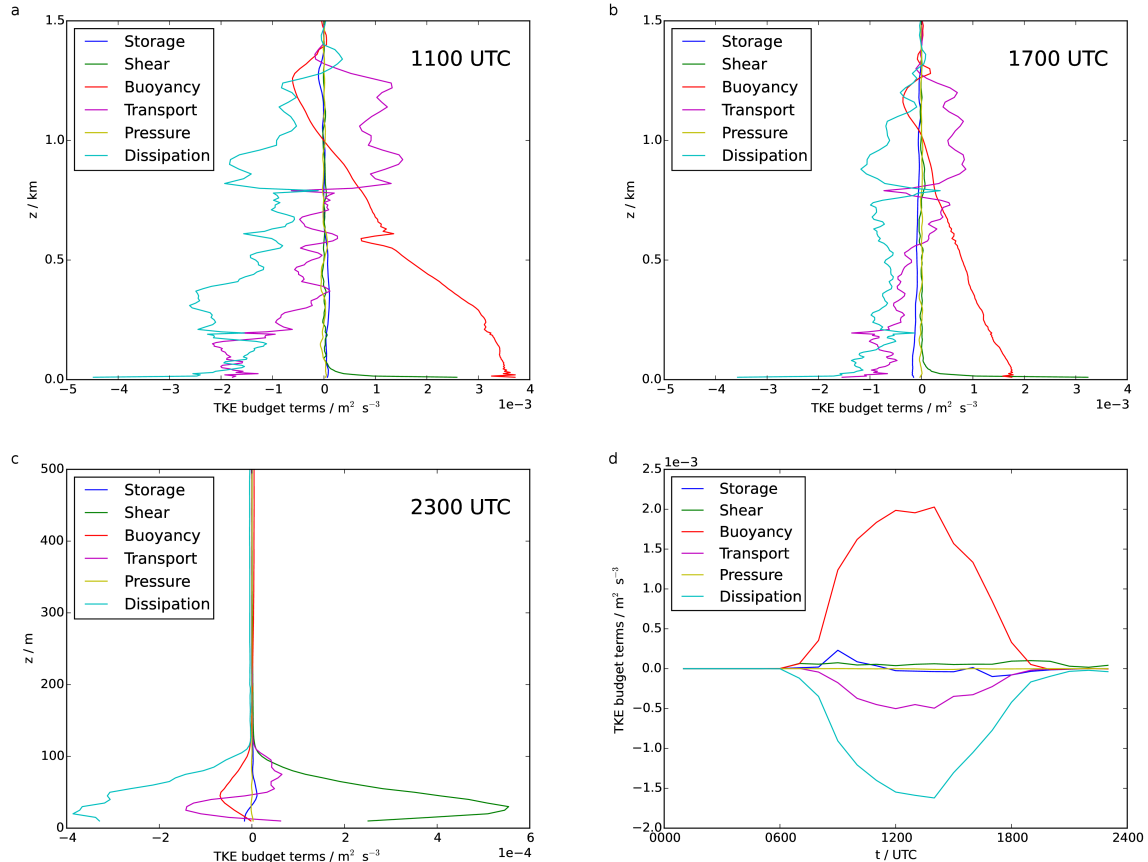

Figure 4. Vertical structure of the TKE budget components storage, shear, buoyancy production, turbulent transport, pressure correlation and dissipation for 1100 UTC, 1700 UTC and 2300 UTC in a, b and c. Time development of the integrated TKE budget components up to the height of the BL in $\mathrm{d}$. 
Atmos. Chem. Phys. Discuss., doi:10.5194/acp-2015-995, 2016

\subsection{TKE budget}

The turbulent kinetic energy budget reads as (Stull (1988)):

$$
\begin{aligned}
& \underbrace{\frac{\partial \bar{e}}{\partial t}}_{\text {Storage }}=-\underbrace{\left(\overline{u^{\prime} w^{\prime}} \frac{\partial u}{\partial z}+\overline{v^{\prime} w^{\prime}} \frac{\partial v}{\partial z}\right)}_{\text {Shear }}+\underbrace{\frac{g}{\overline{\Theta_{0}} \overline{w^{\prime} \Theta^{\prime}}}}_{\text {Buoyancy Production }} \\
& -\underbrace{\frac{\partial \overline{w^{\prime} e^{\prime}}}{\partial z}}_{\text {Turbulent Transport }}-\underbrace{\frac{1}{\rho_{0}} \frac{\partial \overline{w^{\prime} p^{\prime}}}{\partial z}}_{\text {Pressure Correlation }}-\underbrace{\epsilon}_{\text {Dissipation }}
\end{aligned}
$$

In this representation, $u^{\prime}, v^{\prime}, w^{\prime}, \Theta^{\prime}, p^{\prime}$ and $e^{\prime}$ are the turbulent fluctuations of the velocity components $u, v, w$, the potential temperature $\Theta$, the pressure $p$ and the turbulent kinetic energy $e . \Theta_{0}$ is the reference potential temperature at the ground. $\epsilon$ represents the dissipation rate and is calculated as residuum from all other contributions. $\bar{e}$ corresponds to the mean turbulent kinetic energy from Equation (5). The overbar indicates a time and area average.

Figure 4 represents an analysis of the TKE budget terms at selected times. In Fig. 4a, the vertical distribution of the different TKE budget terms in Equation (6) at 1100 UTC are shown, calculated as horizontal mean with central differences in the vertical. The TKE budget terms are maximal in the BL and approach zero at the top of the BL at roughly $1.5 \mathrm{~km}$. This height of the inversion layer corresponds to Fig. 1. The contribution from buoyancy production is large with a maximum in the lowest few hundred meters, whereas shear shows a maximum only close to the surface. The turbulent transport moves TKE from the lower BL to the upper BL with a net divergence and loss of TKE in the lower part and a net convergence and production of TKE in the upper part. The contributions from storage and pressure correlation are rather small, almost an order of magnitude smaller than the other TKE budget terms. The maximum of the dissipation is reached close to the surface where TKE production is largest, mainly influenced by the buoyancy production. Above roughly $800 \mathrm{~m}$, the contribution from turbulent transport dominates the dissipation.

The same vertical TKE budget distribution is shown in Fig. $4 \mathrm{~b}$ for 1700 UTC. In general, the vertical structure is rather similar to $1100 \mathrm{UTC}$, only the magnitude of the individual components differ. At 1700 UTC the contribution of buoyancy production is smaller, evoked by the smaller amount of the surface flux in the late afternoon close to the ET. This also results in lower contributions from turbulent transport and dissipation. The shear term is rather similar with a slightly larger value close to the surface. The storage and pressure correlation are again rather small.

The vertical TKE budget distribution for an SBL situation is shown in Fig. 4c for 2300 UTC. Here, the vertical axis is limited at $500 \mathrm{~m}$, as the TKE budget terms are rather small in the RL. Further, 
Atmos. Chem. Phys. Discuss., doi:10.5194/acp-2015-995, 2016 budget terms.

In Fig. $4 \mathrm{~d}$, the TKE budget terms are vertically integrated up to the top of the BL. The height of the BL is determined by the maximum of the vertical gradient of the potential temperature following Sullivan et al. (1998). The buoyancy production directly correlates with the diurnal cycle. The maximum in the prescribed diurnal cycle appears at 1200 UTC, whereas the maximum in buoyancy in the simulation persists two hours longer even if the surface fluxes are already decreasing. The diurnal cycle dependence occurs also in the turbulent transport. The dissipation correlates with the other components. Storage and pressure correlation are again rather small. In comparison to other studies like Beare (2008) or Blay-Carreras et al. (2014), the contribution from shear is small. This underestimation could be related to the assumption of a horizontally homogeneous surface. It will be tested in the following chapter.

415 The vertical TKE budget structures (Figs. 4a-c) reveal a strong dependency of the individual terms on the diurnal cycle, especially in the lowest $200 \mathrm{~m}$. The temporal evolution in Fig. $4 \mathrm{~d}$ confirms this finding.

\section{Impact of the surface heterogeneity on shear}

The simulation described above is hereafter referred to as simulation A. To investigate the influence of the horizontal distribution of the surface roughness on shear, simulation A is continued after $6 \mathrm{~h}$ of calculation with different surface conditions in simulations B, C and D, as summarised in Table 2 . The investigation starts at 0600 UTC and is limited to the CBL phase, as the individual components of the TKE budget terms are orders of magnitude larger at day than at night.

In Fig. 5a, the shear terms of the four different simulations are vertically integrated over the BL height from 0700 UTC to 1100 UTC, similar to Fig. 4d. All three simulations with a heterogeneous surface show a larger contribution of shear to the TKE budget. Adding obstacles in simulation B increases the factor of shear by an order of magnitude. Doubling the height of the obstacles in simulation $\mathrm{C}$ further increases the amount of shear by a factor of roughly $\frac{1}{3}$. Decreasing the area covered by obstacles leads to a smaller amount of shear by a factor of roughly $\frac{2}{3}$ in simulation $\mathrm{D}$ in comparison to simulation B.

In Fig. 5b, the vertical profiles of the four different simulations A to D are plotted for the lowest $200 \mathrm{~m}$ at 1100 UTC (logarithmic y axis). The amount of the vertically integrated shear in Fig. 5a is mainly determined by the amount of shear in the lowest few meters. In the lowest levels, both, the 
Atmos. Chem. Phys. Discuss., doi:10.5194/acp-2015-995, 2016

Manuscript under review for journal Atmos. Chem. Phys.
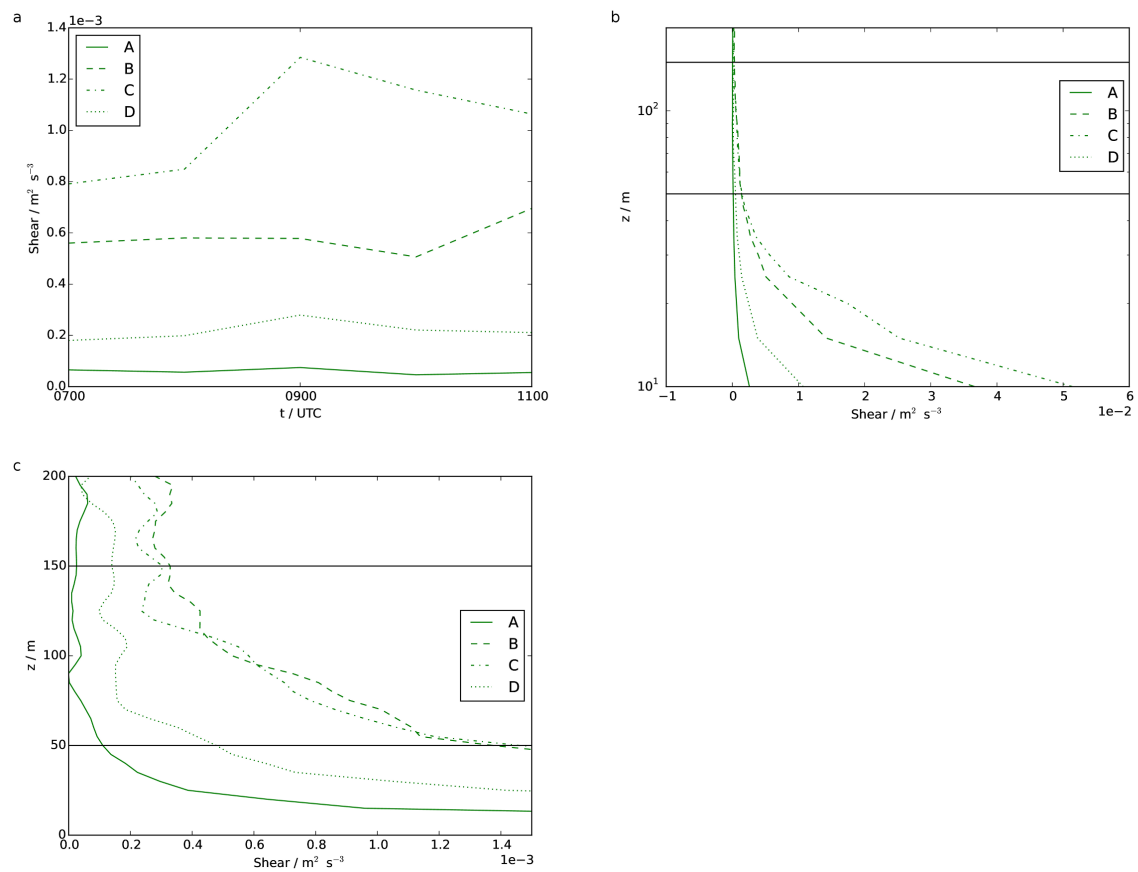

Figure 5. Time development of the integrated shear up to the height of the BL for simulations A, B, C and D in a. Vertical structure of shear for the four different simulations in $\mathrm{b}$ and zoomed in with a detailed view from 50 $\mathrm{m}$ to $150 \mathrm{~m}$ height in $\mathrm{c}$. The solid lines mark $50 \mathrm{~m}$ and $150 \mathrm{~m}$ in height.

height of the obstacles and the fraction covered by them influence the amount of shear. The effect of the height of the obstacles is only prevalent in the lowest roughly $50 \mathrm{~m}$. The vertical profiles above are overlapping for simulations $\mathrm{B}$ and $\mathrm{C}$. The effect of the covered domain fraction is prevalent up to higher levels. The generalised result from Figs. 5a and $\mathrm{b}$ is a larger amount of shear in the BL under heterogeneous surface conditions. The vertically integrated shear increases for higher obstacles or for a larger fraction of the domain covered with obstacles.

Figure 5c shows a section of Fig. 5b. Here the lowest $200 \mathrm{~m}$ are plotted with a special interest in the height from $50 \mathrm{~m}$ to $150 \mathrm{~m}$. Considering homogeneous surface conditions in simulation $\mathrm{A}$, the amount of shear is one order of magnitude smaller in comparison to simulations B, C and D. In both heights of $50 \mathrm{~m}$ and $150 \mathrm{~m}$ the shear contribution of simulations B and C are almost overlapping. The height of the obstacles does no longer seem to influence the shear. At least if the obstacle is small in comparison to the height where the rotor of a wind turbine operates. Here we tested an impact up to $\frac{1}{5}$ of the bottom tip height of $50 \mathrm{~m}$. The fraction of the domain covered by the obstacle, however, still seems to be important at $50 \mathrm{~m}$ as well as at $150 \mathrm{~m}$, with the same percentage impact at 
Atmos. Chem. Phys. Discuss., doi:10.5194/acp-2015-995, 2016

Manuscript under review for journal Atmos. Chem. Phys.

Published: 26 January 2016

(c) Author(s) 2016. CC-BY 3.0 License.
Atmospheric

Chemistry

and Physics

Discussions
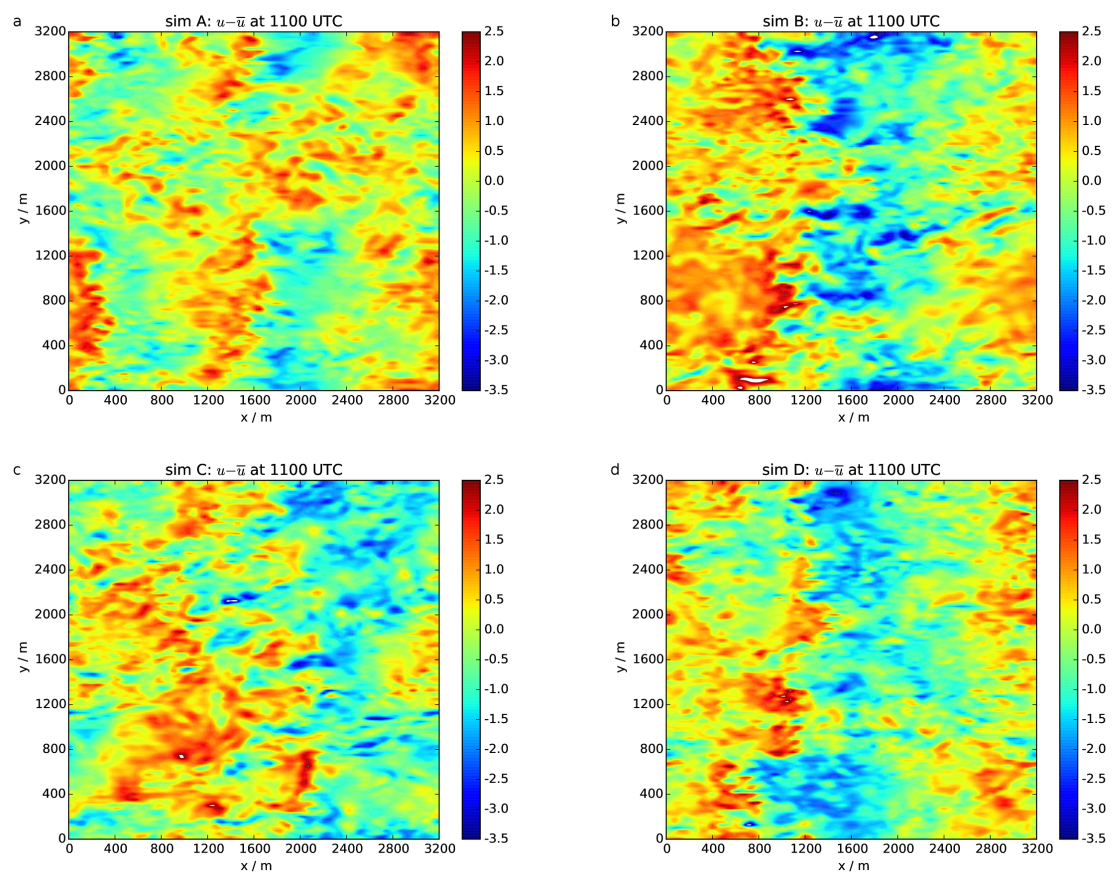

Figure 6. The deviation of the mean zonal velocity from the instantaneous value in $\mathrm{m} \mathrm{s}^{-1}$ at $1100 \mathrm{UTC}$ for simulations A, B, C and D.

these heights in comparison to simulation A and simulations B and C.

The investigation of the surface heterogeneity reveals a strong impact on the amount of shear in the lowest $200 \mathrm{~m}$ in height. A larger fluctuation of $u-\bar{u}$ in Figs. 6a-d at 1100 UTC in simulations $\mathrm{B}, \mathrm{C}$ and $\mathrm{D}$ in comparison to simulation $\mathrm{A}$ verifies this impact. The fluctuations are comparable in simulations $\mathrm{B}$ and $\mathrm{C}$ and they are even larger in comparison to simulation D.

\section{Discussion}

For the validation of the complete diurnal cycle of an ABL evolution, our model results were compared to measurements. The overall temporal evolution of the ABL is well captured by the LES, especially, the height of the ABL follows closely the radiosonde observation for a selected IOP during the BLLAST experiment. The evolution is comparable to the results from Blay-Carreras et al. (2014).

One point of deviation between measurement and simulation is the difference in height of the tran- 
sition from a convective stratification towards a neutral stratification of the potential temperature profile at 1100 UTC and 1700 UTC. In our set-up, the surface fluxes are contributing directly to the temperature of the lowest level controlled by the subgrid-scale model. In addition, the e-folding scale in the exponential height distribution of the surface fluxes impacts the temperature, especially in the lowest levels. A different value of the e-folding scale will affect the height of transition. Another difference between the measurement and the simulation represents the surface condition. The surface flux measurements are performed over a heterogeneous surface whereas in simulation A we consider a homogeneous surface. This could also have an effect on the transition height.

Further, above $1300 \mathrm{~m}$ there is a difference in the $\Theta$ profile between measurement and simulation. We suspect this deviation to be caused by gravity waves or other mesoscale processes. However, as we are focusing on the altitude range relevant for wind energy applications, we leave this problem open.

Another point of deviation is the difference in the potential temperature in the BL at 2300 UTC. The colder temperature close to the ground in the measurements could be achieved in the simulation by applying a stronger cooling at night in the lowest levels, whereas the warmer temperature in the residual layer can be achieved by a weaker cooling in the corresponding height. However, we are considering a constant radiative cooling with height. Further, we prescribe a symmetric surface flux distribution around 1200 UTC and the surface flux measurements also do not indicate a stronger or weaker cooling at night. The colder temperature in the lowest levels, however, can be caused by additional large-scale effects, which we do not include in our simulation, e.g. an advection of colder air close to the surface advecting from the mountains as part of the mountain-plain circulation.

The diurnal cycle impact investigation on wind reveals a larger vertical gradient of $u$ in the lowest $200 \mathrm{~m}$ in the SBL phase. This results in a larger gradient of the forces acting on the blades at individual heights during the SBL phase, as $F \approx u^{2}$ following Hansen (2008). The vertical gradient in the active force leads to an asymmetric fatigue loading of a wind turbine at night, which has an effect on e.g. the life time of the wind turbine.

Considering the individual TKE budget terms, the general vertical structure of shear, buoyancy production, turbulent transport and dissipation are in agreement with Stull (1988). At daytime the buoyancy driven structure with little sensitivity to shear in the CBL state is in agreement with the results in e.g. Moeng and Sullivan (1994) and Beare (2008). At night the domination of shear is in agreement with the results in e.g. Moeng and Sullivan (1994). A comparison to Blay-Carreras et al. (2014)

500 is also conform regarding the vertical dependence and the order of magnitude of the individual TKE budget terms. Further, the contributions from the individual TKE budget terms are in agreement with 
Atmos. Chem. Phys. Discuss., doi:10.5194/acp-2015-995, 2016

Manuscript under review for journal Atmos. Chem. Phys.

Published: 26 January 2016

(c) Author(s) 2016. CC-BY 3.0 License.

Nilsson et al. (2015) for the 1st of July 2011 of the BLLAST field campaign.

The heterogeneity has a strong effect on the amount of shear. The effect is important considering

a non homogeneous surface in nature. Shear contributes to the total amount of TKE in the atmosphere, especially, in the lowest few hundred meters which are relevant for wind turbines. The type of heterogeneity (type B, C or D) does not affect the difference in loading of a wind turbine between top tip at $150 \mathrm{~m}$ and bottom tip at $50 \mathrm{~m}$, as the vertical gradient in this height range is roughly the same for all three simulations. The type of heterogeneity is, however, important for the individual amount of loading turbulence transfers onto the wind turbine blades, which is larger for simulation B and $\mathrm{C}$ in comparison to simulation $\mathrm{D}$. The amount of shear also influences the wake structure of the wind field. A larger amount of shear correlates with a higher amount of ambient turbulence, leading to an intensified entrainment of ambient air. These effects are by a factor of five smaller at $150 \mathrm{~m}$ in comparison to $50 \mathrm{~m}$.

\section{Conclusions}

A complete diurnal evolution of an ABL was simulated using the LES model EULAG. For this purpose, typical forcing parameters as the sensible heat flux at the surface, the subsidence and the radiative cooling were taken from observations during the BLLAST field campaign. The impact of the different phases during the diurnal cycle on wind, atmospheric turbulence and the TKE budget components were investigated, focusing on the lowest $200 \mathrm{~m}$ in which wind turbines operate. Furthermore, we studied the influence of surface heterogeneities on the shear in the ABL.

The potential temperature profiles of the radiosonde measurements are successfully reproduced for a complete diurnal cycle, starting at 0000 UTC. The transition from an SBL towards a CBL in the morning is simulated with the diurnal cycle method from Beare (2008). For the transition from a CBL back to an SBL in the evening, an interpolation method is applied. The reproduction of the complete diurnal cycle of the ABL for the BLLAST dataset with the LES model EULAG validates our methods to simulate the ABL evolution and the different transition periods.

A detailed investigation of the wind field, the atmospheric turbulence and the individual TKE budget terms in Equation (6) is performed in the lowest $200 \mathrm{~m}$ to expose the impact of the individual phases of the diurnal cycle on these physical variables which are relevant for wind energy applications. The velocity gradient in an SBL phase is approximately an order of magnitude larger than in the CBL phase. The atmospheric turbulence has a maximum during the CBL phase and a minimum during the SBL phase. This is in agreement with the TKE budget, which is dominated by a buoyancy driven structure with little sensitivity to shear during day and by shear during night. The maximum of both, 

dividual TKE budget terms and therefore the atmospheric turbulence are a few orders of magnitude smaller than at day. In this way, our results are in general agreement with published knowledge of the dominant ABL processes (e.g Stull (1988), Moeng and Sullivan (1994), Beare (2008), Bhaganagar and Debnath (2014) or Bhaganagar and Debnath (2015)).

The investigation of the turbulence structure further results in a dependency of shear on the surface heterogeneity. Considering realistic conditions, the Earth's surface is not homogeneous. The heterogeneity has a strong impact on the amount of shear, especially in the lowest few metres, which is exactly the region were the interaction between the wind field and the wind turbine wake takes place. The magnitude of shear increases with the degree of surface heterogeneity.

As widely known, the different phases of the ABL diurnal cycle control the wind field and the atmospheric turbulence (e.g Stull (1988), Moeng and Sullivan (1994), Beare (2008), Bhaganagar and Debnath (2014) or Bhaganagar and Debnath (2015)). The stages and transitions between them can be simulated with the LES model EULAG applying the validated numerical techniques. The influence of the amount of turbulence in the flow on the structure of the wake has been tested in experimental studies (e.g. Medici and Alfredsson (2006), Chamorro and Porté-Agel (2009), Zhang et al. (2012)), as well as in simulations (e.g. Troldborg et al. (2007), Wu and Porté-Agel (2012)), resulting in a faster wake recovery for higher turbulence intensity levels of the incoming flow field. This represents a sensitivity of the wake structure towards the individual phases of the diurnal cycle (Emanuel et al. (2015)). Similar assumptions has been confirmed for the SBL phase by Bhaganagar and Debnath (2014) and Bhaganagar and Debnath (2015) with a detailed investigation of the dependency of the wake on the vertical gradient of the wind. Further, the surface heterogeneity also strongly impacts the amount of TKE. From this investigation results a dependency of the wind field and the atmospheric turbulence on the diurnal cycle. The individual phases of the diurnal cycle determine the flow conditions in the lowest $200 \mathrm{~m}$ of the ABL and, therefore, the loading a wind turbine is exposed to as well as the wake structure behind a wind turbine.

For the CBL phase and the transition phases, to our knowledge, no numerical studies have been conducted accounting for real time atmospheric conditions in combination with the atmospheric turbulence. According to our results regarding the atmospheric turbulence and the vertical velocity gradient dependency on the individual phases, this is a necessary investigation. Further, placing an emphasis on heterogeneous surface will correspond much more to realistic conditions which are prevalent in the atmosphere. Therefore, our future research will focus on combining the ABL simulations presented in this paper at different phases of the diurnal cycle with a wind turbine simulation (Englberger and Dörnbrack (2015)) for different surface conditions. 
Atmos. Chem. Phys. Discuss., doi:10.5194/acp-2015-995, 2016

Manuscript under review for journal Atmos. Chem. Phys.

\section{References}

Aitken, M. L., Kosović, B., Mirocha, J. D., and Lundquist, J. K.: Large eddy simulation of wind turbine wake dynamics in the stable boundary layer using the Weather Research and Forecasting Model, Journal of Renewable and Sustainable Energy, 6, 033 137, doi:10.1063/1.4885111, 2014.

Balsley, B. B., Svensson, G., and Tjernström, M.: On the scale-dependence of the gradient Richardson number in the residual layer, Bound-Lay Meteorol, 127, 57-72, doi:10.1007/s10546-007-9251-0, 2008.

Beare, R. J.: The Role of Shear in the Morning Transition Boundary Layer, Bound-Lay Meteorol, 129, 395-410, doi:10.1007/s10546-008-9324-8, 2008.

Beare, R. J., Macvean, M. K., Holtslag, A. A. M., Cuxart, J., Esau, I., Golaz, J.-C., Jimenez, M. A., Khairoutdinov, M., Kosović, B., Lewellen, D., Lund, T. S., Lundquist, J. K., Mccabe, A., Moene, A. F., Noh, Y., Raasch, S., and Sullivan, P.: An Intercomparison of Large-Eddy Simulations of the Stable Boundary Layer, Bound-Lay Meteorol, 118, 247-272, doi:10.1007/s10546-004-2820-6, 2006.

Bhaganagar, K. and Debnath, M.: Implications of Stably Stratified Atmospheric Boundary Layer Turbulence on the Near-Wake Structure of Wind Turbines, Energies, 7, 5740-5763, doi:10.3390/en7095740, 2014.

Bhaganagar, K. and Debnath, M.: The effects of mean atmospheric forcings of the stable atmospheric boundary layer on wind turbine wake, Journal of Renewable and Sustainable Energy, 7, 013124 , doi:10.1063/1.4907687, 2015.

Blay-Carreras, E., Pino, D., Vilà-Guerau de Arellano, J., van de Boer, A., De Coster, O., Darbieu, C., Hartogensis, O., Lohou, F., Lothon, M., and Pietersen, H.: Role of the residual layer and large-scale subsidence on the development and evolution of the convective boundary layer, Atmos Chem Phys, 14, 4515-4530, doi:10.5194/acp-14-4515-2014, 2014.

Carlson, M. A. and Stull, R. B.: Subsidence in the nocturnal boundary layer, J Clim Appl Meteorol, 25, 10881099, doi:10.1175/1520-0450(1986)025<1088:SITNBL>2.0.CO;2, 1986.

Chamorro, L. P. and Porté-Agel, F.: A Wind-Tunnel Investigation of Wind-Turbine Wakes: Boundary-Layer Turbulence Effects, Bound-Lay Meteorol, 132, 129-149, doi:10.1007/s10546-009-9380-8, 2009.

Chamorro, L. P. and Porté-Agel, F.: Effects of Thermal Stability and Incoming Boundary-Layer Flow Characteristics on Wind-Turbine Wakes: A Wind-Tunnel Study, Bound-Lay Meteorol, 136, 515-533, doi:10.1007/s10546-010-9512-1, 2010.

Conzemius, R. and Fedorovich, E.: Bulk models of the sheared convective boundary layer: Evaluation through large eddy simulations, J Atmos Sci, 64, 786-807, doi:10.1175/JAS3870.1, 2007.

Deardorff, J. W.: Three-dimensional numerical study of the height and mean structure of a heated planetary boundary layer, Bound-Lay Meteorol, 7, 81-106, doi:10.1007/BF00224974, 1974a.

Deardorff, J. W.: Three-dimensional numerical study of turbulence in an entraining mixed layer, Bound-Lay Meteorol, 7, 199-226, doi:10.1007/BF00227913, 1974b.

Dörnbrack, A. and Schumann, U.: Numerical simulation of turbulent convective flow over wavy terrain, BoundLay Meteorol, 65, 323-355, doi:10.1007/BF00707032, 1993.

610 Doyle, J. D., Gaberšek, S., Jiang, Q., Bernardet, L., Brown, J. M., Dörnbrack, A., Filaus, E., Grubišic, V., Kirshbaum, D. J., Knoth, O., et al.: An intercomparison of T-REX mountain-wave simulations and implications for mesoscale predictability, Mon Weather Rev, 139, 2811-2831, doi:10.1175/MWR-D-10-05042.1, 2011. 
Atmos. Chem. Phys. Discuss., doi:10.5194/acp-2015-995, 2016

Manuscript under review for journal Atmos. Chem. Phys.

Emanuel, K., Hoss, F., Keith, D., Kuang, Z., Lundquist, J., and Miller, L.: Workshop on Climate Effects of Wind Turbines, B Am Meteorol Soc, doi:10.1175/BAMS-D-15-00231.1, 2015. Verlag, Berlin Heidelberg, Germany, 2013.

Emeis, S.: Current issues in wind energy meteorology, Meteorol Appl, 21, 803-819, doi:10.1002/met.1472, 2014.

Englberger, A. and Dörnbrack, A.: The impact of atmospheric boundary layer turbulence on a wind turbine wake, Bound-Lay Meteorol, in review, 2015.

Fedorovich, E., Nieuwstadt, F., and Kaiser, R.: Numerical and laboratory study of a horizontally evolving convective boundary layer. Part I: Transition regimes and development of the mixed layer, J Atmos Sci, 58, 70-86, doi:10.1175/1520-0469(2001)058<0070:NALSOA>2.0.CO;2, 2001.

Grimsdell, A. W. and Angevine, W. M.: Observations of the afternoon transition of the convective boundary layer, J Appl Meteorol, 41, 3-11, doi:10.1175/1520-0450(2002)041<0003:OOTATO>2.0.CO;2, 2002.

Hansen, M. O.: Aerodynamics of wind turbines, vol. 2, Earthscan, London and Sterling, UK and USA, 2008.

Kühnlein, C., Smolarkiewicz, P. K., and Dörnbrack, A.: Modelling atmospheric flows with adaptive moving meshes, J Comput Phys, 231, 2741-2763, doi:10.1016/j.jcp.2011.12.012, 2012.

Lipps, F. B. and Hemler, R. S.: A scale analysis of deep moist convection and some related numerical calculations, J Atmos Sci, 39, 2192-2210, doi:10.1175/1520-0469(1982)039<2192:ASAODM>2.0.CO;2, 1982.

Lothon, M., Lohou, F., Pino, D., Couvreux, F., Pardyjak, E. R., Reuder, J., Vilà-Guerau de Arellano, J., Durand, P., Hartogensis, O., Legain, D., Augustin, P., Gioli, B., Lenschow, D. H., Faloona, I., Yagüe, C., Alexander, D. C., Angevine, W. M., Bargain, E., Barrié, J., Bazile, E., Bezombes, Y., Blay-Carreras, E., van de Boer, a., Boichard, J. L., Bourdon, a., Butet, a., Campistron, B., de Coster, O., Cuxart, J., Dabas, a., Darbieu, C., Deboudt, K., Delbarre, H., Derrien, S., Flament, P., Fourmentin, M., Garai, a., Gibert, F., Graf, a., Groebner, J., Guichard, F., Jiménez, M. a., Jonassen, M., van den Kroonenberg, a., Magliulo, V., Martin, S., Martinez, D., Mastrorillo, L., Moene, a. F., Molinos, F., Moulin, E., Pietersen, H. P., Piguet, B., Pique, E., RománCascón, C., Rufin-Soler, C., Saïd, F., Sastre-Marugán, M., Seity, Y., Steeneveld, G. J., Toscano, P., Traullé, O., Tzanos, D., Wacker, S., Wildmann, N., and Zaldei, a.: The BLLAST field experiment: Boundary-Layer Late Afternoon and Sunset Turbulence, Atmos Chem Phys, 14, 10 931-10 960, doi:10.5194/acp-14-109312014, 2014.

Mahrt, L.: Nocturnal boundary-layer regimes, Bound-Lay Meteorol, 88, 255-278, doi:10.1023/A:1001171313493, 1998.

Mazzitelli, I. M., Cassol, M., Miglietta, M. M., Rizza, U., Sempreviva, a. M., and Lanotte, a. S.: The role of subsidence in a weakly unstable marine boundary layer: a case study, Nonlinear Proc Geoph, 21, 489-501, doi:10.5194/npg-21-489-2014, 2014.

Medici, D. and Alfredsson, P. H.: Measurements on a wind turbine wake: 3D effects and bluff body vortex shedding, Wind Energy, 9, 219-236, doi:10.1002/we.156, 2006.

Mirocha, J. D., Kosović, B., Aitken, M. L., and Lundquist, J. K.: Implementation of a generalized actuator disk 
Atmos. Chem. Phys. Discuss., doi:10.5194/acp-2015-995, 2016

Manuscript under review for journal Atmos. Chem. Phys.

Moeng, C.-H. and Sullivan, P. P.: A comparison of shear-and buoyancy-driven planetary boundary layer flows, J Atmos Sci, 51, 999-1022, doi:10.1175/1520-0469(1994)051<0999:ACOSAB>2.0.CO;2, 1994.

Nadeau, D. F., Pardyjak, E. R., Higgins, C. W., Fernando, H. J. S., and Parlange, M. B.: A simple model for the afternoon and early evening decay of convective turbulence over different land surfaces, Bound-Lay Meteorol, 141, 301-324, doi:10.1007/s10546-011-9645-x, 2011.

Naughton, J. W., Heinz, S., Balas, M., Kelly, R., Gopalan, H., Lindberg, W., Gundling, C., Rai, R., Sitaraman, J., and Singh, M.: Turbulence and the Isolated Wind Turbine, 6th AIAA Theoretical Fluid Mechanics Conference, Honolulu, Hawaii, 27-30 June 2011, 1-19, 2011.

Nieuwstadt, F. T.: The turbulent structure of the stable, nocturnal boundary layer, J Atmos Sci, 41, 2202-2216, doi:10.1175/1520-0469(1984)041<2202:TTSOTS>2.0.CO;2, 1984.

Nilsson, E., Lohou, F., Lothon, M., Pardyjak, E., Mahrt, L., and Darbieu, C.: Turbulence Kinetic Energy budget during the afternoon transition-Part 1: Observed surface TKE budget and boundary layer description for 10 intensive observation period days, Atmos Chem Phys Discuss, 15, 29 747-29 805, doi:10.5194/acpd-1529747-2015, 2015.

Pino, D., Vilà-Guerau de Arellano, J., and Duynkerke, P. G.: The contribution of shear to the evolution of a convective boundary layer, J Atmos Sci, 60, 1913-1926, doi:10.1175/15200469(2003)060<1913:TCOSTT>2.0.CO;2, 2003.

Pino, D., Jonker, H. J., De Arellano, J. V.-G., and Dosio, A.: Role of shear and the inversion strength during sunset turbulence over land: characteristic length scales, Bound-Lay Meteorol, 121, 537-556, doi:10.1007/s10546-006-9080-6, 2006.

Porté-Agel, F., Lu, H., and Wu, Y.-t.: A large-eddy simulation framework for wind energy applications, in: The Fifth International Symposium on Computational Wind Engineering, Chapel Hill, 2010.

Prusa, J. M., Smolarkiewicz, P. K., and Wyszogrodzki, A. A.: EULAG, a computational model for multiscale flows, Comput Fluids, 37, 1193-1207, doi:10.1016/j.compfluid.2007.12.001, 2008.

Smolarkiewicz, P. K. and Charbonneau, P.: EULAG, a computational model for multiscale flows: An MHD extension, J Comput Phys, 236, 608-623, doi:10.1016/j.jcp.2012.11.008, 2013.

Smolarkiewicz, P. K. and Margolin, L. G.: On forward-in-time differencing for fluids: extension to a curviliniear framework, Mon Weather Rev, 121, 1847-1859, doi:10.1175/15200493(1993)121<1847:OFITDF>2.0.CO;2, 1993.

Smolarkiewicz, P. K. and Margolin, L. G.: MPDATA: A Finite-Difference Solver for Geophysical Flows, J Comput Phys, 140, 459-480, doi:10.1006/jcph.1998.5901, 1998.

Smolarkiewicz, P. K. and Prusa, J. M.: Forward-in-time differencing for fluids: simulation of geophysical turbulence, in: Turbulent Flow Computation, Kluwer Academic Publishers, Boston, USA, 207-240, 2002.

Smolarkiewicz, P. K. and Prusa, J. M.: Towards mesh adaptivity for geophysical turbulence: continuous mapping approach, Int J Numer Meth Fl, 47, 789-801, doi:10.1002/fld.858, 2005.

Smolarkiewicz, P. K. and Pudykiewicz, J. A.: A class of semi-Lagrangian approximations for fluids, J Atmos Sci, 49, 2082-2096, doi:10.1175/1520-0469(1992)049<2082:ACOSLA>2.0.CO;2, 1992.

Smolarkiewicz, P. K., Sharman, R., Weil, J., Perry, S. G., Heist, D., and Bowker, G.: Building resolving large-eddy simulations and comparison with wind tunnel experiments, J Comput Phys, 227, 633-653, doi:10.1016/j.jcp.2007.08.005, 2007. 
Atmos. Chem. Phys. Discuss., doi:10.5194/acp-2015-995, 2016

Manuscript under review for journal Atmos. Chem. Phys. 0469(1996)053<2015:ECBVTS>2.0.CO;2, 1996. doi:10.1023/A:1000231524314, 1997.

Sorbjan, Z:: Large-eddy simulations of the baroclinic mixed layer, Bound-Lay Meteorol, 112, 57-80, doi:10.1023/B:BOUN.0000020161.99887.b3, 2004.

Sorbjan, Z.: A numerical study of daily transitions in the convective boundary layer, Bound-Lay Meteorol, 123, 365-383, doi:10.1007/s10546-006-9147-4, 2007.

Stull, R. B.: An Introduction of Boundary Layer Meteorology, Dordrecht, Kluwer Academic, 1988.

Sullivan, P. P., Moeng, C.-H., Stevens, B., Lenschow, D. H., and Mayor, S. D.: Structure of the Entrainment Zone Capping the Convective Atmospheric Boundary Layer, J Atmos Sci, 55, 3042-3064, doi:10.1175/15200469(1998)055<3042:SOTEZC>2.0.CO;2, 1998.

705 Tian, W., Ozbay, A., Yuan, W., Sarakar, P., and Hu, H.: An experimental study on the performances of wind turbines over complex terrain, in: 51st AIAA Aerospace Sciences Meeting including the New Horizons Forum and Aerospace Exposition, 07-10 January 2013, Grapevine, Texas, USA, 1-14, 2013.

Troldborg, N., Sørensen, J. N., and Mikkelsen, R.: Actuator Line Simulation of Wake of Wind Turbine Operating in Turbulent Inflow, J Phys Conf Ser, 75, 012 063, doi:10.1088/1742-6596/75/1/012063, 2007.

710 Wehner, B., Siebert, H., Ansmann, A., Ditas, F., Seifert, P., Stratmann, F., Wiedensohler, A., Apituley, A., Shaw, R., Manninen, H., et al.: Observations of turbulence-induced new particle formation in the residual layer, Atmos Chem Phys, 10, 4319-4330, doi:10.5194/acp-10-4319-2010, 2010.

Wu, Y. T. and Porté-Agel, F.: Large-Eddy Simulation of Wind-Turbine Wakes: Evaluation of Turbine Parametrisations, Bound-Lay Meteorol, 138, 345-366, doi:10.1007/s10546-010-9569-x, 2011.

715 Wu, Y. T. and Porté-Agel, F.: Atmospheric Turbulence Effects on Wind-Turbine Wakes: An LES Study, Energies, 5, 5340-5362, doi:10.3390/en5125340, 2012.

Zhang, W., Markfort, C. D., and Porté-Agel, F.: Near-wake flow structure downwind of a wind turbine in a turbulent boundary layer, Exp Fluids, 52, 1219-1235, doi:10.1007/s00348-011-1250-8, 2012.

Zhang, W., Markfort, C. D., and Porté-Agel, F.: Wind-Turbine Wakes in a Convective Boundary Layer: A Wind-Tunnel Study, Bound-Lay Meteorol, 146, 161-179, doi:10.1007/s10546-012-9751-4, 2013. 
Atmos. Chem. Phys. Discuss., doi:10.5194/acp-2015-995, 2016

Manuscript under review for journal Atmos. Chem. Phys.

Published: 26 January 2016

(c) Author(s) 2016. CC-BY 3.0 License.

Table 1. Spatial horizontal resolutions $\Delta x$ and $\Delta y$ and the number of horizontal grid points $n$ and $m$ for the individual phases of a diurnal cycle.

\begin{tabular}{c|c|c} 
BL type & $n \times m$ & $\Delta x=\Delta y$ \\
\hline SBL start & $128 \times 128$ & $6.25 \mathrm{~m}$ \\
\hline MT & $128 \times 128$ & $12.5 \mathrm{~m}$ \\
\hline CBL & $128 \times 128$ & $25 \mathrm{~m}$ \\
\hline ET & $256 \times 256$ & $12.5 \mathrm{~m}$ \\
\hline SBL end & $512 \times 512$ & $6.25 \mathrm{~m}$ \\
\hline
\end{tabular}

Table 2. The main surface characteristics of the three simulations with heterogeneous surfaces referred to as simulation $\mathrm{B}, \mathrm{C}$ and $\mathrm{D}$.

\begin{tabular}{c|c|c} 
simulation & obstacle size & obstacle distance \\
\hline B & $100 \mathrm{~m} \times 100 \mathrm{~m} \times 5 \mathrm{~m}$ & $100 \mathrm{~m}$ \\
\hline $\mathrm{C}$ & $100 \mathrm{~m} \times 100 \mathrm{~m} \times 10 \mathrm{~m}$ & $100 \mathrm{~m}$ \\
\hline $\mathrm{D}$ & $100 \mathrm{~m} \times 100 \mathrm{~m} \times 5 \mathrm{~m}$ & $200 \mathrm{~m}$ \\
\hline
\end{tabular}

